\title{
Avatares en el lazo social y constitución narcisista. Análisis de una situación clínica*
}

\section{Viscissitudes in social bonding and narcissistic constitution. Analysis of a clinical situation}

\author{
María Jimena Mendoza**
}

\begin{abstract}
Resumen
A partir de la demanda a salud mental en un centro de salud, este artículo analiza las dificultades en el lazo con semejantes de niños varones entre seis y once años. Muestra, además, cómo estas dificultades nos reenvían a trabajar la instauración de las figuras de la alteridad y la constitución narcisista, así como también las vicisitudes de ser alojado por la pareja parental y las instituciones como la escuela y el centro de salud.
\end{abstract}

Palabras claves: semejante - extranjero narcisismo - identificaciones - filiación contrato narcisista

\section{Abstract}

Based on the demand for mental health in a Health Center, this article analyzes the difficulties in bonding with peers of boys between 6 and 11 years old. We demonstrate how these difficulties led us to work on the establishment of figures of supporting alterity and narcissistic constitution, as well as the vicissitudes of being housed by the parental couple and institutions such as the school and the Health Centre.

Keywords: Similar - Foreigner Narcissism - Identifications - Filiation - Narcissist Contract

\section{Introducción}

El propósito de este trabajo es enriquecer el análisis de la demanda al área de salud mental en un centro de salud del distrito oeste de Rosario. Específicamente, la que se realiza en relación con niños de entre seis y once años con dificultades en el lazo. Las derivaciones son realizadas mayormente por las escuelas.

Entendemos por lazo social "la institución de una sociedad para los individuos, pero es también la institución del tipo de individuos pertinentes para esa sociedad (Lewkowicz, 2008, p.56).

Nuestra hipótesis en esta experiencia es que la modalidad del lazo con el otro devela la inconsistencia de la figura del semejante

\footnotetext{
* Artículo escrito sobre la base del trabajo final integrador para la Carrera de Especialización en Psicología Clínica, Institucional y Comunitaria (UNR). "¿Por sus efectos lo reconoceremos? Dificultades en la constitución narcisista” del que soy autora bajo la dirección de Mg. Jaime Fernández Miranda. Fue presentado en 2014 y aprobado en 2015.

** Psicóloga. Especialista en Psicología Clínica, Institucional y Comunitaria (UNR).jimenamendoza08@gmail.com
} 
(con todo el sesgo amoroso y la aceptación de la alteridad que esta figura supone); $y$, una preeminencia de la figura del extranjero devenido ajenidad ominosa y amenazante, es decir, una versión persecutoria del extranjero. Estas dificultades en el lazo podrían ser una de las razones de las conductas violentas entre los niños.

Trabajamos con un caso testigo que presenta el perfil de demanda descripto que permitió analizar las vicisitudes en el alojamiento de un niño por parte de la pareja parental y sus efectos en la constitución narcisista. Para ello, fueron modificados el nombre y referencias al niño para preservar su identidad y resguardar la confidencialidad.

A partir del abordaje de estos niños podemos constatar cierta fragilidad en la instauración de la frontera entre el yo y el no-yo. Esto plantea un inevitable conflicto con las figuras de la alteridad. La hipótesis de trabajo es que esta dificultad se debe a una falla en la constitución narcisista. La categoría de narcisismo reenvía a la constitución del yo, a la tensión-identificación con el otro. La problemática del otro (el otro en mí mismo, el otro como extranjero) se sitúa en el meollo de la constitución narcisista.

Si el otro está alojado en el corazón del yo, ¿cómo se estructura la frontera entre el yo y el no-yo, entre el interior y el exterior, entre el sujeto y la alteridad? ¿Cómo se constituye la figura del extranjero? ¿Y la del semejante? ¿De qué modo lo extranjero que, según conocidos desarrollos freudianos, en los inicios es amenazante, se vuelve plausible de ser amado? ¿Qué condiciones son necesarias para poder estar con otros? ¿De qué recursos se vale un niño o un adulto para armarse una vida?

Finalmente, el concepto de contrato narcisista (Aulagnier,2010) posibilitó ubicar la inscripción social de la pareja parental y del niño, al mismo tiempo que rastrear las dificultades en el alojamiento de un niño por parte de las instituciones.

\section{Vicisitudes en la constitución narci- sista a la luz de una situación clínica}

\section{a. El caso Ciro}

Ciro llegó al centro de salud con once años, por episodios de agresión hacia otros niños en la escuela. Asistía al taller de serigrafía ${ }^{1}$. A veces, podía estar y trabajar pero otras veces llegaba en patota y el trabajo se volvía imposible. Por momentos, hasta desbarataba el taller. Fueron los coordinadores quienes consideraron que Ciro necesitaba un espacio de terapia individual. Luego fue derivado a un espacio psicoterapéutico.

Después de varios intentos para que llegase a la consulta, Alejandra, la madre de Ciro, comenzó a realizar entrevistas con una psicóloga del centro de salud. Allí se despejaron las dificultades que tenía Alejandra: síntomas en su cuerpo (palpitaciones, adormecimiento de miembros inferiores), desorientación témporo-espacial. Por esto la psicóloga decidió iniciar un trabajo con Alejandra y derivó a Ciro con una colega que no participaba del taller de serigrafía.

\footnotetext{
${ }^{1}$ El taller de serigrafía es un espacio que funciona dentro del centro de salud y al que asisten niños y niñas (aunque la mayoría son varones) con dificultades en el lazo con semejantes. Este espacio se enmarca dentro del proyecto terapéutico de cada participante. Quienes coordinan el espacio son un tallerista y dos psicólogas.
} 
En la única entrevista con la psicóloga de Ciro, Alejandra se mostró muy preocupada por su hijo mayor. Walter tenía deciséis años, había dejado la escuela y se encontraba en circuitos de consumo. Ella no podía entender cómo había terminado así: confió en él y la desilusionó. Había sido un chico al que le iba muy bien en la escuela. En cambio con Ciro, "se me va a ir la vida".

Alejandra viene de una familia con siete hermanos. Todos se encontraban en circuitos de consumo y delincuencia. Ella era la única que escapaba a eso. Sin embargo, dejaba a Walter al cuidado de estos hermanos. En la entrevista aparece una dificultad para alojar a sus hijos y cediéndolos a sus hermanos, que para ella constituían una pesadilla. Cuando se le preguntó por los nombres de Ciro, ya que era conocido como Silvio en la escuela y Ciro en el centro de salud, dijo que estaba anotado como Silvio porque no lo había podido anotar como Ciro. A ella le gustó ese nombre por un niño que había desaparecido en esa época. Silvio era, también, el nombre del papá de Ciro.

En palabras de Alejandra, Silvio, el padre de los chicos, era un hombre que había vivido en el campo y "se crió solo". Trabajaba durante todo el día, motivo por el cual no asistió a las distintas entrevistas a las que fue convocado. Ella decía que él no quería asistir porque era ignorante y no sabría cómo hablar con las psicólogas.

Esta situación fue abriendo signos de interrogación en torno al lugar de Ciro para su madre, que estaba muy tomada por el sufrimiento que le provocaba la situación de su hijo mayor. Y, al mismo tiempo, en el taller aparece algo sintomático: buscábamos a un niño que ya estaba en el taller, haciendo invisible a Ciro. Algo de él no terminaba de poder ser alojado y parecía estar perdiéndosenos.

Su padre tampoco parecía acusar recibo de lo que el niño hacía cuando andaba en banda. No daba crédito a las quejas de los vecinos: pedradas contra sus casas, pequeños robos en una feria barrial y correteos con otros niños sobre el techo de la escuela.

El taller de serigrafía había logrado constituirse en una referencia, lo que habilitó que Ciro y otros dos niños con los que se juntaba fueran al centro de salud a jugar. Buscaban a alguna de las psicólogas y elegían un juego. Jugaban en la sala de espera, luego lo devolvían y se iban.

Los primeros adultos en registrar las dificultades de Ciro fueron la docente de la escuela y la vice-directora. Ellas pidieron una reunión con las psicólogas para trabajar la derivación al centro de salud. Para la escuela, el problema se ubicaba en la distancia entre este niño/alumno que concurría y el niño/alumno que ellas esperaban.

En el primer encuentro con la psicóloga, Ciro dibujó un corazón y lo pintó de rosa. Luego se le propuso jugar con plastilinas.

La psicóloga le preguntó si sabía por qué asistía a sesiones de psicología. Respondió que se portaba mal en la escuela. Ella le dijo que a él le pasaban cosas y que estaba ahí para que ella lo ayudase con lo que le pasaba.

Ciro contó que se peleaba en la escuela con otros chicos por defender a los "tontitos" y a las mujeres, a los que no se podían defender.

Comenzó a armar una casita con muchos detalles: cama, mesa, baño, mesa de luz, un perro, un gato. Pero la casa no tenía 
techo ni puerta. Y afuera había luces, alarmas, un perro guardián, rejas para defender la casa de los que querían entrar. Al finalizar la sesión y acordar para la próxima semana, hizo un gran bollo de plastilina con la casita y todos los elementos. La psicóloga propuso trabajar con arcilla.

En el encuentro siguiente, preguntó dónde había comprado la arcilla. Mientras trabajaban, preguntó dónde vivía la psicóloga. Comentó sorprendido: “QQué lejos! ¿Y te venís hasta acá?" cuando le respondió que vivía en el centro.

Durante los siguientes encuentros, mientras armaban una casita con arcilla, siguió con sus preguntas: “¿Tenés hijos?” "¿Salís a bailar?” "¿Por qué estudiaste psicología?”

En otra sesión relató que estaba en quinto grado y comenzó a preguntar qué venía después de la primaria. La psicóloga le respondió, la secundaria. ¿Y después? La terciaria o universidad, los posgrados, los post-doctorados.

Preguntó hasta donde había llegado ella y comentó que él quería terminar de estudiar y ser policía.

A veces iba acompañado de su mamá a la consulta y, otras veces, solo.

En los juegos que se fueron armando en los encuentros, se fue despejando que Ciro atacaba como un modo de defensa. Había algo fallido en su defensa ante el otro. También el robo era un modo de defenderse del otro, allí donde no podía armar algo propio.

En sus preguntas hacia su psicóloga, estaba preguntando por la vida. Casi como contrapunto de una madre encerrada todo el día en su casa, a veces perdida y que no se enteraba de lo que pasaba cuando Ciro estaba en la calle.
Después de un tiempo, Alejandra dejó de asistir a las entrevistas y Ciro también.

En ese momento, la psicóloga de Ciro participaba de un proyecto en la escuela a la que asistía el niño y lo buscó algunas veces para recordarle que lo iba a estar esperando. Pero no volvió.

\section{b. Fallas en la frontera narcisista y en la instauración de lo propio}

La situación de Ciro es un problema por los episodios de violencia que se generan con sus compañeros en un ámbito como el escolar o el taller de serigrafía. Si ataca para defenderse, y lo hace en un espacio que debiera funcionar como exogámico, es porque algo de la operación que diferencia lo familiar de lo extra familiar no ha sido posible.

Para comenzar a ubicar cómo se constituye la figura del semejante y el extranjero, volveremos a Freud. En "Pulsiones y destinos de pulsión" (Freud, 2010a) plantea que un ser vivo inerme, como en el caso de un niño, comienza a recibir estímulos exteriores de los cuales puede escapar mediante una acción muscular; pero también recibe estímulos de los que no puede escapar. Estos últimos son la marca de un mundo interior.

Esta marca comenzará a diferenciar un interior y un exterior, quedando ubicado en el exterior lo que le resulte displacentero. El odio quedará ubicado en relación al objeto exterior que provoca displacer. Pero si este objeto se convierte en fuente de placer, vuelve a ser incorporado por el yo. De este modo, el yo coincide con lo placentero y el no-yo es siempre una pura ajenidad amenazante y odiada.

La etapa narcisista es relevada por la eta- 
pa del objeto. Placer y displacer significan relaciones del yo con el objeto. Cuando el objeto es fuente de sensaciones placenteras, se establece una tendencia motriz que quiere acercarlo al yo, incorporarlo a él; entonces hablamos de la "atracción” que ejerce el objeto dispensador de placer y decimos que amamos al objeto. A la inversa, cuando el objeto es fuente de sensaciones de displacer, una tendencia se afana en aumentar la distancia entre él y el yo, en repetir el intento originario de huida frente al mundo exterior emisor de estímulos. Sentimos la repulsión del objeto, y lo odiamos; este odio puede, después, acrecentarse convirtiéndose en la inclinación a agredir al objeto, con el propósito de aniquilarlo (Freud, 2010a, p.131).

Estos desarrollos freudianos, sitúan la primera percepción de lo ajeno -en el lactante- bajo el sesgo de lo persecutorio. Y aunque Freud no lo explicite, el yo-placer purificado no es sólo un tiempo originario en la constitución del narcisismo y del otro, sino que también contornea un modo de funcionamiento narcisista en que todo lo extranjero es odiado y amenazante y el amor, por lo tanto, sólo puede ser amor de sí: se ama en el otro sólo aquello que puede ser asimilado a lo propio.

El narcisismo de las pequeñas diferencias devela una lógica narcisista en la cual la alteridad emerge siempre bajo un sesgo persecutorio y por ello debe ser aniquilada. Y es que, Freud lo señala con lucidez, la diferencia parece ser una amenaza a la identidad del yo. En el yo de placer purificado, el reconocimiento amoroso del otro como semejante (idéntico y diferente al mismo tiempo) queda anulado. La figura del extranjero es siempre amenazante. Esta idea tiene una gran presencia en la clínica con ciertos pacientes que podríamos agrupar bajo el rótulo de trastornos narcisistas.

¿Se trata en Ciro de esta modalidad narcisista? La tensión constante que se instala entre el niño y los otros, ¿da cuenta de un yo de placer purificado incapaz de operar un reconocimiento amoroso del otro como semejante, quedando el lazo dominado por la figura de una extranjería persecutoria $y$ aborrecida? ¿Es la agresividad de Ciro un modo de afirmación narcisista, es decir, un modo de evitar ser fagocitado por una mismidad que diluya su propia singularidad, su propia diferencia respecto del otro? Hay ciertos elementos en el encuentro con Ciro, que nos llevan a pensar las fallas narcisistas del niño en una dirección sensiblemente diferente a esta.

Pensamos que Ciro debe realizar una operación de expulsión en algunos momentos, ya que hay un cierre que no se ha producido. El otro no termina de inscribirse como extraño ya que tampoco puede inscribirse lo extraño en él mismo. El otro se vuelve intrusivo debido a que hay una frontera que se constituyó de modo endeble. Es lo que despliega Ciro en su juego, cuando arma una casa sin techo ni ventanas. Cuando en un niño la frontera narcisista está establecida, las puertas y las ventanas de la casa que su propietario puede cerrar y abrir según la ocasión, son lugares de intercambio con el exterior. A falta de puertas, en Ciro, las alarmas, las rejas y el perro guardián vienen a resguardar una frontera narcisista agujereada. Los dientes filosos del perro guardián se sitúan en los agujeros del espacio narcisista.

Entonces, en este niño, la tensión cons- 
tante con el extranjero da cuenta de una falla en la instauración de la frontera narcisista y, por lo tanto, en la constitución de lo propio. La inconsistencia de lo propio conmina a Ciro a una lucha constante con el extranjero.

Ahora bien, ¿cómo se constituye lo propio? Lo propio se constituye a través de un trabajo de apropiación, y para eso es necesaria una donación del otro, del otro encarnado en los padres, pero también del otro social. La apropiación es una operación del heredero. Es poder hacer algo con aquello que heredó.

Ricardo Rodulfo (2012) señala significativas diferencias en las modalidades de apropiación, las cuales dan cuenta de diferencias diagnósticas:

No es lo mismo que el niño extraiga elementos para subjetivarse apuntalado en el otro, a que se vea limitado a extraer del otro; lo segundo caracterizará precisa y específicamente el trastorno narcisista no psicótico, mientras que el extraer apuntalado en el otro es propio de un niño más apropiado de lo propio. (p.186)

En este niño más apropiado de lo propio (Rodulfo, 2012) a través del juego entre lo que el otro dona y lo que el niño extrae se va constituyendo un espacio propio, un cuerpo, un tiempo. En Ciro esta operatoria aparece obstaculizada allí donde su padre dice no haber recibido don (se crió solo), en el cual el don del nombre que el padre podría hacer no lo nombra para la madre. Su nombre, para la ella, lo pone en la secuencia de un niño perdido.
¿Acaso Ciro no pregunta por cómo armarse una vida con sus preguntas hacia su psicóloga? ¿Hay un intento de apuntalarse en ella para diferenciarse? ¿Hasta dónde llegó ella, hasta dónde quiere llegar él, hasta dónde se puede llegar? Porque en definitiva, construir la categoría del extraño, es poder ubicarse a sí mismo como extraño al otro, al deseo del otro, intentando construir, así, una posición respecto a su propio desear.

Sin embargo, para que esta operación sea posible, tiene que producirse un cerramiento del espacio narcisista.

En Ciro hay una tentativa de cerramiento del propio espacio (alarmas, perros, rejas) que pareciera dejarlo librado a una tensión mortífera con el otro.

\section{c. Ciro sostiene el taller}

El niño deja de asistir a las entrevistas con la psicóloga pero va al taller de serigrafía. ¿Qué le ofrece este espacio que lo sostiene? Este lugar le dona la posibilidad de ser un niño entre otros, de tramitar la figura del semejante y el extranjero a través del juego; permitiéndole soportar lo extraño y la tensión agresiva porque hay allí adultos que median entre ellos.

Y, al mismo tiempo, lo filia a la cultura. Esto permite una restauración del contrato narcisista (Aulagnier, 2010) que se fundamenta en una apuesta por parte del conjunto que anticipa el lugar al que el yo del niño advendrá, posibilitándole no quedar atrapado por el discurso parental.

Winnicott (2011b), en su libro Deprivación y delincuencia, plantea que el niño buscará en otros familiares o en la escuela lo que no pudo hallar en su hogar. Buscará un marco que le dé estabilidad y seguridad para 
no enloquecer al quedar abandonado a sus pulsiones destructivas.

Los niños que llegan al centro de salud por dificultades en el lazo con sus semejantes no sostienen el tratamiento terapéutico pero sí el taller de serigrafía, un espacio para encontrarse con otros que los alojan pero que también pone condiciones, y al cual pueden aportar algo pero del que también reciben algo. Allí encuentran no sólo un alivio del sufrimiento sino una experiencia que va más allá de ellos, una experiencia que -con Winnicott (2011a)- podríamos llamar experiencia cultural:

He usado la expresión experiencia cultural como una ampliación de la idea de los fenómenos transicionales y del juego, sin estar seguro de poder definir la palabra "cultura". Por cierto que el acento recae en la experiencia. Al utilizar el vocablo cultura pienso en la tradición heredada. Pienso en algo que está contenido en el acervo común de la humanidad, a lo cual pueden contribuir los individuos y los grupos de personas, $y$ que todos podemos usar si tenemos algún lugar en que poner lo que encontremos. (2011a, p.133)

Y páginas más adelante:

$\mathrm{Y}$ yo afirmo que los mismos fenómenos que representan la vida y la muerte para nuestros pacientes esquizoides o fronterizos aparecen en nuestras experiencias culturales. Estas son las que aseguran la continuidad en la raza humana, que va más allá de la existencia personal. Doy por sentado que constituyen una continuidad directa del juego, el jugar de quienes aún no han oído hablar de los juegos. (Winnicott, 2011a, p.135)

La experiencia cultural permite construir por otras vías aquello que el niño no pudo encontrar en su ambiente. Un espacio de ilusiones compartidas donde a través del juego sea posible filiarse a un proyecto con otros sin masificarse. A través de la experiencia cultural compartida, el niño deviene heredero y transmisor de su cultura.

Retornando sobre la problemática narcisista y a las demandas a salud mental por dificultades en el lazo social, podemos decir que estos espacios institucionales propician la instauración de un proyecto identificatorio en estos niños.

Piera Aulagnier (2010) define el proyecto identificatorio como:

la autoconstrucción continua del Yo por el Yo, necesaria para que esta instancia pueda proyectarse en un movimiento temporal, proyección de la que depende la propia existencia del Yo. Acceso a la temporalidad y acceso a una historización de lo experimentado van de la mano: la entrada en escena del Yo es, al mismo tiempo, entrada en escena de un tiempo historizado (p. 168-169).

Se trata de ofrecer un lugar en el que los adultos que acompañan a estos niños puedan donarles una mirada diferente, que puedan creer que otro futuro es posible para ellos. 


\section{Reflexiones finales}

Las dificultades en el lazo que exponen estos niños cuestionan a las instituciones productoras de infancia como la familia y la escuela, pero también a las prácticas en el marco de un centro de salud.

El problema presenta dos dimensiones. Por un lado la cuestión clínica y, por otro, la dimensión y efectos de determinadas políticas que instituyen subjetividad.

Respecto a nuestra responsabilidad como psicoanalistas, se vuelve necesario volver a pensar los conceptos a la luz de nuevas modalidades de sufrimiento que aparecen de forma cada vez más descarnada. Asimismo, es menester recuperar el gesto freudiano de producir en diálogo con otros, sabiendo que se trata de un problema que excede al campo psicoanalítico, pero que hay herramientas dentro de nuestro campo que nos pueden balizar el camino.

Estas modalidades de sufrimiento también impactan intensamente en quienes trabajamos con ellas, problemática que ha sido bien abordada por Winnicott (2011b). La elaboración teórica de estas modalidades violentas de padecimiento infantil, nos protege del riesgo de asistir impotentes al horror que provoca tanta pulsión de muerte desligada.

La capacidad lúdica y la creatividad resultan esenciales. Las prácticas transformadoras que habiliten otros modos de ver a los pacientes requieren de la capacidad de invención en la construcción de dispositivos que excedan el trabajo específico de cada disciplina, sin perder de vista que esto no es simplemente un problema de salud.

Consideramos que hay un horizonte de trabajo posible con los niños que aborda- mos en este trabajo, que consiste en poder pensar espacios que puedan alojarlos, espacios de encuentros con otros que los saquen de la inmediatez abriendo la posibilidad de la estructuración de un proyecto identificatorio.

Pero también tiene que existir el esfuerzo por pensar qué lugar es posible para los padres y madres de estos niños, a través de qué dispositivos pueden volver a ser incluidos en la sociedad que los excluyó. El horizonte de trabajo es una apuesta a pensar el lugar que un dispositivo como el taller de serigrafía tendría en torno a los modos de producir contrato y de trabajar la relación al semejante.

En este sentido, virando hacia la dimensión más política, para que estos dispositivos no se conviertan en un fin en sí mismos, sino que puedan articularse y ayudar en la construcción de trayectos vitales, debe haber políticas de Estado que puedan ser solidarias de un nuevo modelo social que vuelva a incluir a quienes quedaron por fuera del contrato narcisista; políticas que le devuelvan la dignidad de ser miembros plenos de la sociedad en la que viven; políticas sociales, de trabajo, de vivienda, de educación, salud y seguridad.

Quedan muchas preguntas pendientes en relación a esta problemática. ¿Qué pasa cuando estos niños llegan a la adolescencia? ¿Cuáles son los modelos identificatorios que se les ofrecen a los adolescentes? ¿Qué futuro es posible para un adolescente de un barrio humilde?

Es necesario pensar los dispositivos en función de los problemas que leemos. Son estos problemas los que permiten nuevas teorizaciones. La teoría puesta en función de la clínica. 
Si, como plantea Piera Aulagnier (2010), las grandes lecciones de la clínica vienen en forma de fracaso, quizás sea hora de preguntarnos qué podemos aprender de estos fracasos en la constitución narcisista.

\section{Referencias}

- Aulagnier, P. (2010). La violencia de la interpretación: Del pictograma al enunciado. Buenos Aires: Amorrortu.

- Freud, S. (2010a). Pulsiones y destinos de pulsión, en Obras completas. Tomo XIV. (14 edición en castellano). Buenos Aires, Argentina: Amorrortu.

- Freud, S. (2010b). Introducción del narcisismo, en Obras completas. Tomo XIV.
Buenos Aires: Amorrortu.

- Freud, S. (2010c). Psicología de las masas y análisis del yo, en Obras completas. Tomo XVIII. Buenos Aires: Amorrortu.

- Lewkowicz, I. (2008). Pensar sin Estado: La subjetividad en la era de la fluidez. Buenos Aires: Paidós.

- Rodulfo, R. (2012) Jugar en el vacio, en Rodulfo, R. (comp.) Trastornos narcisistas no psicóticos: Estudios psicoanalíticos sobre problemáticas del cuerpo, el espacio y el aprendizaje en niños y adolescentes. Buenos Aires: Paidós.

- Winnicott, D. (2011a). Realidad y juego. Buenos Aires: Gedisa.

- Winnicott, D. (2011b). Deprivación y delincuencia. Buenos Aires: Paidós. 